\title{
Effects of acetaminophen and ibuprofen monotherapy in febrile children: a meta-analysis of randomized controlled trials
}

\author{
Ning Kuo ${ }^{1}$, Nien-Yin Su${ }^{1}$, Sen-Kuang Hou ${ }^{1,2}$, Yi-No Kang ${ }^{1,3,4,5,6}$
}

\author{
${ }^{1}$ Department of Emergency Medicine,Taipei Medical University Hospital, Taiwan \\ 2Department of Emergency Medicine, School of Medicine, College of Medicine, \\ Taipei Medical University, Taiwan \\ ${ }^{3}$ Evidence-Based Medicine Center, Wan Fang Hospital, Taipei Medical University, Taiwan \\ ${ }^{4}$ Institute of Health Policy and Management, College of Public Health, National \\ Taiwan University, Taiwan \\ ${ }^{5}$ Cochrane Taiwan, Taipei Medical University, Taipei, Taiwan \\ ${ }^{6}$ Department of Health Care Management, College of Health Technology, National \\ Taipei University of Nursing Health Sciences, Taipei, Taiwan
}

Submitted: 16 April 2021; Accepted: 4 August 2021

Online publication: 22 August 2021

Arch Med Sci 2022; 18 (4): 965-981

DOI: https://doi.org/10.5114/aoms/140875

Copyright $@ 2022$ Termedia \& Banach

\section{A bstract}

Introduction: When a child presents with fever in the clinical encounter, parents are usually concerned about alleviating the fever. However, the indications for selecting an appropriate drug from the most commonly used antipyretic drugs, acetaminophen and ibuprofen, remain unclear. The purpose of this study was to assess the efficacy and safety of acetaminophen and ibuprofen in febrile children through a systematic review with meta-analysis of randomized controlled trials (RCTs).

Material and methods: Cochrane, Embase, and PubMed databases were searched for the relevant RCTs. Two authors individually extracted information on trial design, demography, rate of fever resolution, body temperature, and overall adverse events. Data were pooled mainly using a random-effects model; however, because of some sparse data, Peto odds ratios (PORs) were used for outcomes of fever resolution and adverse event. 95\% confidence intervals (Cls) were also presented.

Results: In total, 26 RCTs $(n=4137)$ fulfilled eligibility criteria. Pooled estimates demonstrated that acetaminophen led to significantly lower fever resolution rates than ibuprofen did (POR $=0.91,95 \% \mathrm{Cl}: 0.84-0.98 ; l^{2}=0 \%$ ) in the subgroup of trials with a mean age of $<2$ years. However, the treatment-time interaction model for body temperature demonstrated that the fever resolution effect was mainly from the time factor based on the available data (effect size $=-0.20 ; 95 \% \mathrm{Cl}:-0.30$ to $-0.11 ; I^{2}=6.9 \%$ ). Acetaminophen demonstrated lower overall adverse event rates than ibuprofen $(P O R=0.71$; $\left.95 \% \mathrm{Cl}: 0.58-0.87 ; l^{2}=0 \%\right)$.

Conclusions: The effects of ibuprofen are similar to acetaminophen even in children with mean age of approximately 5 years. Nevertheless, acetaminophen is safer than ibuprofen, particularly in children approximately 5 years old.

Key words: fever resolution, fever, pediatric, paracetamol, ibuprofen.

\section{Introduction}

Children experience fever more frequently than adults. Fever is a crucial immune response of the body that helps us eliminate invad-

\author{
Corresponding authors: \\ Yi-No Kang \\ Taipei Medical \\ University Hospital \\ Wan Fang Hospital \\ Taipei Medical \\ University \\ National Taiwan University \\ Taiwan \\ E-mail: \\ academicnono@gmail.com \\ Sen-Kuang Hou \\ Taipei Medical University \\ Hospital \\ E-mail: 992001@h.tmu.edu.
}


ing pathogens [1], and is a common symptom in various pediatric diseases, particularly infectious diseases [2]. In general, when febrile children present to a clinic, physicians focus on determining and treating the underlying cause of the pyrexia, whereas parents are more concerned about alleviating the fever itself. Fever is also a common reason for visiting physicians. This phenomenon is called "fever phobia" [3]. The role of antipyretic medication is to ease the child's discomfort caused by fever and prevent dehydration [4]. The most commonly recommended antipyretic drugs are acetaminophen and ibuprofen [5]. Acetaminophen has a longer history, starting in the 1950s when it replaced aspirin to prevent Reye's syndrome; currently, its labeled dose is $10-15 \mathrm{mg} / \mathrm{kg}$ every $4 \mathrm{~h}$ in children aged $>3$ months [6]. Ibuprofen, approved for use in febrile children in 1989, is a common over-the-counter medication [7]; currently, its labeled dose is $5-10 \mathrm{mg} / \mathrm{kg}$ every $6-8 \mathrm{~h}$ in children aged $>6$ months.

Ibuprofen is conventionally considered more effective than acetaminophen in the treatment of fever [8], because it has a longer duration of action than does acetaminophen (6-8 vs. 4 h). Nevertheless, acetaminophen demonstrates a low adverse effect risk $[9,10]$. A series of studies have assessed acetaminophen and ibuprofen prescription in the pediatric population. However, to our knowledge, only two systematic reviews have discussed monotherapy of the two medications for febrile children, and both syntheses mixed febrile and non-febrile children [8, 11]. The earlier synthesis, in 2004, only analyzed 10 of the 17 included randomized controlled trials (RCTs) for febrile children, while the other RCTs did not focus on febrile children [8]. Since the meta-analysis also included RCTs regarding pain management in children, the safety of the two medications in the synthesis mixed febrile and non-febrile children. The other meta-analysis published in 2020 had a similar situation, and focused on children under 2 years old [11]. Moreover, six related RCTs on this topic had been published before the previous systematic reviews [12-17]. The most effective clinical practice for using these two antipyretic medications remains unclear [18].

To improve the confidence and understanding in using the two antipyretic medications, updated evidence including all relevant RCTs is required. The study aimed to assess the efficacy and safety of acetaminophen and ibuprofen in febrile children, and the elements of our research question in the PICO form are as follows:

- patients/population/problem: children with fever,

- intervention: acetaminophen,

- comparison: ibuprofen,

- outcome: fever resolution rate, body temperature, and complication rate.

\section{Material and methods}

To appropriately answer our research question, we performed the study adhering to the guidance in the Cochrane Handbook for Systematic Reviews of Interventions [19]. We then referred to the guidelines of Preferred Reporting Items for Systematic Reviews and Meta-Analyses to report our study, including eligibility criteria, data source, evidence selection, data extraction, quality evaluation, data pooling, and result reporting [20]. The protocol for this study has been published on PROSPERO (CRD42020150731).

\section{Eligibility criteria}

Based on the PICO of this study, the authors defined primary eligibility criteria for evidence selection before the search. The inclusion criteria were as follows: (a) patients with fever, (b) population sample represented by a pediatric group aged $<18$ years, (c) therapy comprised at least one arm of acetaminophen and the other arm of ibuprofen for antipyretic treatment, and (d) the study had to be an RCT since RCT is a better study design for evidence regarding effects of intervention according to the recommendation of Cochrane handbook [19]. We did not exclude evidence according to sex, disease, dosage, and administration route.

\section{Data source and evidence selection}

Potential studies were mainly identified from the Cochrane Database of Systematic Reviews (including the Cochrane Central Register of Controlled Trials (CENTRAL)), Embase, and PubMed databases by using relevant keywords about four core elements using the terms fever, pediatric, acetaminophen, and ibuprofen. The relevant keywords consisted of free text and medical subject headings. The Boolean operator "OR" was used to combine synonyms of each core element, and the operator "AND" was applied to connect the four search parts. References were screened using the primary search strategy without any filters for restricting study design, publication date, language, or age (Appendix 1). In addition, Google Scholar was also searched; however, it had no advanced search function. Reference lists of relevant systematic reviews and RCTs were also screened for potential eligible evidence. A final search was performed for potential evidence before March 2021.

To identify eligible evidence, two authors (N.G. and N.Y.S.) independently screened titles and abstracts to eliminate irrelevant references. Subsequently, the full text of the remaining references was retrieved and carefully reviewed. The two authors excluded references according to the eligibility criteria mentioned earlier, and they further eliminated gray literature without details about 
study design, medication information, baseline characteristics, or outcomes during the full-text review step. After the two-step screening process, the two authors simultaneously checked the eligible evidence for the present study. If there was any disagreement related to selected evidence, an experienced researcher was consulted, who also made all final decisions about the included evidence.

\section{Data extraction and quality evaluation}

All eligible evidence for this study was further reviewed for data extraction and quality assessment. The two authors individually extracted studies by publication year, information of trial designs, characteristics of samples, diagnostic measures of fever, the definition of fever, types of intervention, the termination point of the study, and outcome measures. Types of intervention were different dosages and administration routes of acetaminophen and ibuprofen. The primary outcome measures were nonfebrile count; mean body temperature at baseline and 1, 2, 4, and $6 \mathrm{~h}$ after administration of antipyretics based on the pharmacokinetics research [21, 22]; and adverse effects classified by the system (gastrointestinal, respiratory, neurologic, dermatologic, hematologic, ear, nose and throat, and hypothermia). They double-checked data mutually before analysis. Then, the two authors and an experienced researcher had a meeting to resolve disagreements between them through triple-checking and discussion.

Quality evaluation was based on data extraction. To assess the risk of bias, the Cochrane risk-of-bias tool 2 (RoB 2), first released in the Cochrane Handbook for Systematic Reviews of Interventions in 2016 and updated in 2019, was used $[23,24]$. Because the RoB 2 adopts an outcome-oriented approach, the two authors evaluated bias from the randomization process, deviations from intended interventions, missing outcome data, measurement of outcome, and selection of the reported result in each trial of every outcome.

\section{Data synthesis and analysis}

Trial characteristics and patient demographic information were synthesized qualitatively, and relevant outcomes were combined quantitatively. Head-to-head meta-analysis in a random-effects model was performed for quantitative analysis. Because fever resolution and adverse event rates were dichotomous variables, their events and non-events with each medication were used for obtaining the risk ratios and $95 \%$ confidence intervals (Cls). The Peto odds ratio (POR) was also estimated when any sparse cell existed in the fever resolution or adverse event rates. Interpretation of pooled estimates using sparse data was mainly based on POR for statistical robust- ness [19]. Weighted mean differences (WMDs) between acetaminophen monotherapy and ibuprofen monotherapy were estimated based on means, standard deviations, and sample sizes of each variable for each medicine.

To evaluate the quality of the pooled data, small study effects and heterogeneity were tested. The funnel plot and Egger's test were performed to detect small study effects within pooled fever resolution rates, the difference in body temperatures, and adverse event rates. Because body temperatures were reported for multiple time points, a treatment-time interaction model was assessed [25]. Heterogeneity among the included trials was detected using $P^{2}$ statistics. If $l^{2} \geq 50 \%$ or $p$-value $<0.10$ for any outcome, the pooled result was considered highly heterogeneous. Subgroups of measuring time and age range were further analyzed for statistical and clinical heterogeneity. All analyses were performed using STATA for Microsoft Windows (version 14).

After quantitative synthesis of fever resolution, body temperature, and adverse event rates, the Grading of Recommendation, Assessment, Development, and Evaluations (GRADE) was further applied to the overall judgment of each finding for clinical practice [26]. Results of the GRADE evaluation mainly consist of certainty of the evidence, relative effects, and comments. There are four levels of certainty of the evidence: Very Low $(\oplus \bigcirc \bigcirc \bigcirc)$, Low $(\oplus \oplus \bigcirc \bigcirc)$, Moderate $(\oplus \oplus \oplus \bigcirc)$, and High $(\oplus \oplus \oplus \oplus)$.

\section{Results}

Our search yielded a total of 559 articles from the Cochrane $(k=154)$, Embase $(k=144)$, and PubMed $(k=261)$ databases. Four more articles were identified from reference lists of relevant systematic reviews and Google Scholar. Of these, 529 were excluded because they were duplicated $(k=183)$, were irrelevant $(k=88)$, did not include children with fever $(k=67)$, did not compare acetaminophen and ibuprofen monotherapies $(k=131)$, were not RCTs $(k=51)$, were abstracts without details $(k=5)$, and were other documents $(k=4)$. Of the remaining 34 articles, we further excluded 9 because they did not compare acetaminophen and ibuprofen monotherapies. Finally, 26 RCTs were included in this systematic review and meta-analysis [7, 12-17, 27-45]. The flow of article selection is illustrated in Figure 1.

\section{Characteristics and quality of included studies}

The 26 included RCTs recruited 4137 children with fever from Africa, the Americas, Asia, and Europe. These trials were published between 1989 and 2020. Based on available data, the mean age ranged from 1.5 to 6.23 years. Most trials report- 


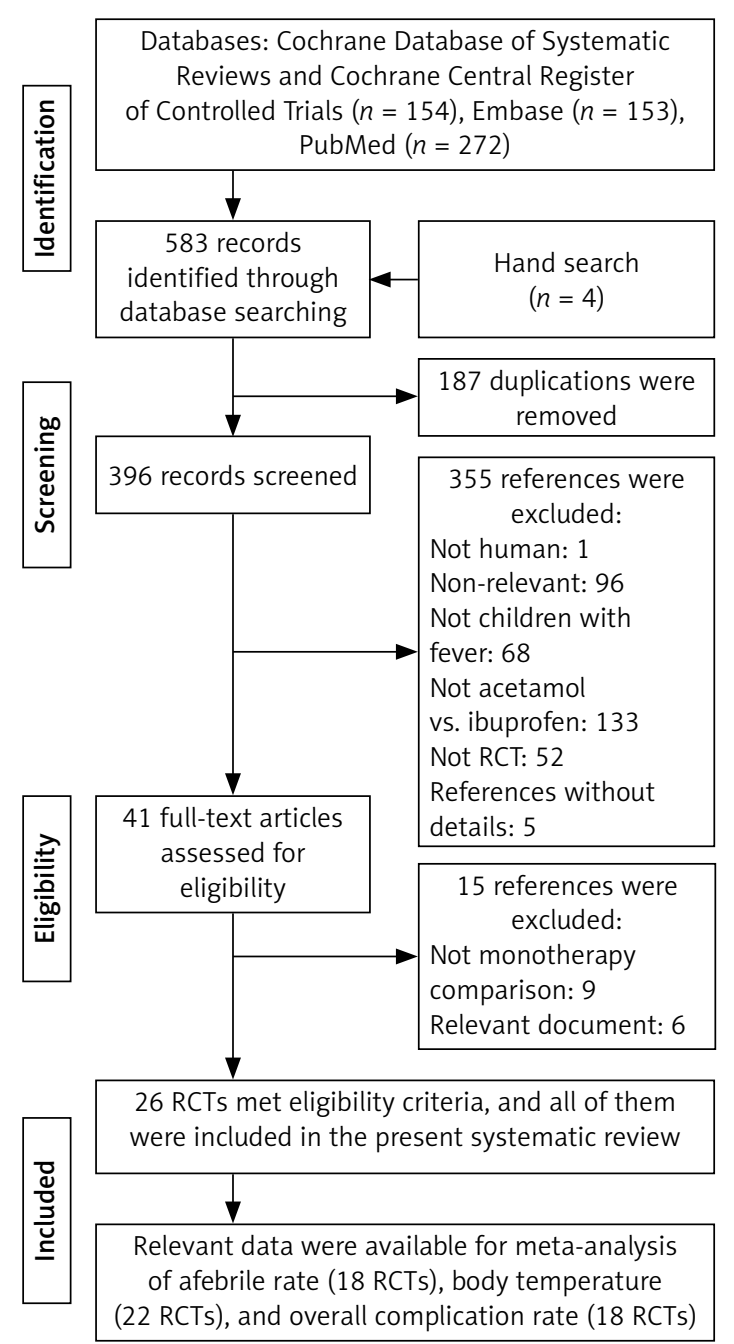

Figure 1. Flow of selection of randomized controlled trials comparing acetaminophen and ibuprofen monotherapies

$R C T$ - randomized controlled trial.

ed that baseline body temperature was $>38.5^{\circ} \mathrm{C}$, except in a trial by Wilson with a temperature of approximately $37.5^{\circ} \mathrm{C}$ in each group and three trials without baseline body temperature $[15,36,37$, 44]. Eight trials clearly declared that children receiving antibiotics were excluded $[13,29-31,34$ 38, 40, 41]. Table I lists demographic information, and Appendix 2 presents the quality of the included RCTs according to the outcome of interest.

\section{Fever resolution rate and body temperature}

Data on fever resolution rates could be derived from 18 RCTs $(n=2734)$. The pooled estimate of fever resolution rates demonstrated that both acetaminophen (931/1329) and ibuprofen (1042/1405) monotherapies led to similar fever resolution rates (Figure 2), and the POR of fever resolution was 0.99 (95\% Cl: 0.97 to 1.001). However, the pooled estimate was highly heterogeneous $\left(I^{2}=72.9 \%\right)$, and high heterogeneity existed be- tween subgroups $\left(P^{2}=52.6 \%, p<0.10\right)$. Egger's test did not detect small study effects (coefficient $=-0.27 ; p>0.05$; Figure 3 ). In the subgroup of trials with a mean age of $<2$ years, notably, acetaminophen monotherapy demonstrated a significantly lower fever resolution rate than did ibuprofen monotherapy (POR $=0.91,95 \% \mathrm{Cl}: 0.84$ to 0.98 ; $R^{2}=0 \%$. No significant difference in fever resolution rates between the two medications could be observed in the subgroups of trials with a mean age between 2 to 5 years old and above 5 years old.

In total, 21 RCTs $(n=3569)$ reported body temperature data. The data for children's body temperature at baseline (22 RCTs) and 1 (7 RCTs, $n=1069), 2$ (7 RCTs, $n=1053), 4$ (6 RCTs, $n=783)$, and 6 ( 5 RCTs, $n=606) \mathrm{h}$ after medication administration were available (Appendix 3). Pooled estimates demonstrated no significant difference in body temperature between acetaminophen and ibuprofen at baseline and 1 and $2 \mathrm{~h}$ after intervention, whereas the pooled estimates were highly heterogeneous. Furthermore, compared with ibuprofen, acetaminophen demonstrated higher body temperatures $4(\mathrm{WMD}=0.27 ; 95 \% \mathrm{Cl}: 0.08$ to 0.45$)$ and 6 (WMD $=0.23$; $95 \% \mathrm{Cl}: 0.02$ to 0.43 ) hours after administration. The treatment-time interaction model, however, demonstrated that the fever resolution effect was mainly from the time factor based on the available data (effect size $=-0.20 ; 95 \% \mathrm{Cl}$ : -0.30 to $-0.11 ; P^{2}=6.9 \%$ ). No significant effect from acetaminophen monotherapy or treatment-time interaction could be observed (Appendix 4).

\section{Safety}

Data on adverse event rates were derived from 18 RCTs $(n=3286)$. A pooled estimate demonstrated that neither acetaminophen nor ibuprofen monotherapy demonstrated a significant difference in overall adverse event rates $(P O R=0.97$; $95 \% \mathrm{Cl}: 0.93$ to 1.01; Figure 4), although high heterogeneity was observed in the pooled estimate $\left(I^{2}=67.1 \%\right)$ and between subgroups $\left(I^{2}=78.4 \%\right.$, $p<0.05)$. The pooled estimate of overall adverse event rates might not be considerably biased by small study effects (coefficient $=-0.20 ; p>0.05$ ). Subgroup analysis demonstrated no significant differences in overall adverse event rates between acetaminophen and ibuprofen monotherapies in trials with a mean age of $<2$ years old as well as mean age between 2 and 5 years old. Significant findings were observed only in trials with a mean age of $>5$ years, where acetaminophen monotherapy demonstrated lower overall adverse event rates than ibuprofen monotherapy (POR = $0.71 ; 95 \% \mathrm{Cl}: 0.58$ to $0.87 ; 1^{2}=0 \%$ ). Table II shows the summary of findings and certainty of evidence regarding the effects of acetaminophen and ibuprofen on afebrile rate and overall complication. 
Table I. Characteristics of the included randomized controlled trials

\begin{tabular}{|c|c|c|c|c|c|c|}
\hline Author & Area & Treatment & Frequency & Form & $\operatorname{Sex}(M / F)$ & Age \\
\hline \multirow{2}{*}{$\begin{array}{l}\text { Alaje et al. } \\
2020\end{array}$} & \multirow{2}{*}{ Africa } & Acetaminophen $15 \mathrm{mg}$ & Single dose & $\mathrm{PO}$ & $35 / 35$ & 2.23 \\
\hline & & Ibuprofen $10 \mathrm{mg}$ & Single dose & $\mathrm{PO}$ & $35 / 35$ & 2.22 \\
\hline \multirow{2}{*}{$\begin{array}{l}\text { Autret et al. } \\
1994\end{array}$} & \multirow[t]{2}{*}{ Europe } & Acetaminophen $10 \mathrm{mg}$ & Q6H & $\mathrm{PO}$ & $43 / 34$ & 1.9 \\
\hline & & Ibuprofen $7.5 \mathrm{mg}$ & Q6H & $\mathrm{PO}$ & $47 / 30$ & 2.06 \\
\hline \multirow{2}{*}{$\begin{array}{l}\text { Autret et al. } \\
1996\end{array}$} & \multirow[t]{2}{*}{ Europe } & Acetaminophen $10 \mathrm{mg}$ & Q6H & $\mathrm{PO}$ & NR & NR \\
\hline & & Ibuprofen $7.5 \mathrm{mg}$ & Q6H & $\mathrm{PO}$ & & \\
\hline \multirow{2}{*}{$\begin{array}{l}\text { Autret et al. } \\
2007\end{array}$} & \multirow[t]{2}{*}{ Europe } & Acetaminophen $15 \mathrm{mg}$ & Q6H & PO & $78 / 72$ & 3.71 \\
\hline & & Ibuprofen $10 \mathrm{mg}$ & Q6H & $\mathrm{PO}$ & $73 / 78$ & 3.84 \\
\hline \multirow{2}{*}{$\begin{array}{l}\text { Celebi et al. } \\
2009\end{array}$} & \multirow{2}{*}{$\begin{array}{c}\text { Middle } \\
\text { East }\end{array}$} & Acetaminophen $15 \mathrm{mg}$ & NR & $\mathrm{PO}$ & $59 / 53$ & 3.96 \\
\hline & & Ibuprofen 10 mg & & $\mathrm{PO}$ & $43 / 41$ & 3.77 \\
\hline \multirow{2}{*}{$\begin{array}{l}\text { Choi et al. } \\
2018\end{array}$} & \multirow[t]{2}{*}{ Asia } & Propacetamol 15/30mg & Single dose & IV & $63 / 62$ & 3 \\
\hline & & Ibuprofen 6 mg & Single dose & $\mathrm{PO}$ & $70 / 68$ & 3 \\
\hline \multirow{2}{*}{$\begin{array}{l}\text { Erlewyn et al. } \\
2006\end{array}$} & \multirow{2}{*}{ Europe } & Acetaminophen $15 \mathrm{mg}$ & Single dose & PO & NR & 1.5 \\
\hline & & Ibuprofen $5 \mathrm{mg}$ & Single dose & PO & & 1.5 \\
\hline \multirow{2}{*}{$\begin{array}{l}\text { Figueras et al. } \\
2002\end{array}$} & \multirow{2}{*}{ Europe } & Acetaminophen 10.65 mg & Single dose & PO & $60 / 39$ & 3.78 \\
\hline & & Ibuprofen 6.67 mg & Single dose & $\mathrm{PO}$ & $52 / 48$ & 3.48 \\
\hline \multirow{2}{*}{$\begin{array}{l}\text { Hay et al. } \\
2008\end{array}$} & \multirow{2}{*}{ Europe } & Acetaminophen $15 \mathrm{mg}$ & $\mathrm{Q} 4 \mathrm{H}$ & PO & $26 / 26$ & 2.39 \\
\hline & & Ibuprofen 10 mg & Q6H & PO & $37 / 15$ & 2.34 \\
\hline \multirow{2}{*}{$\begin{array}{l}\text { Jayawardena } \\
\text { et al. } 2017\end{array}$} & North & Acetaminophen $10-15 \mathrm{mg}$ & Single dose & PO & $71 / 85$ & 4.85 \\
\hline & America & Ibuprofen 7.5 mg & Single dose & PO & $73 / 90$ & 4.36 \\
\hline Kauffman et al. & North & Acetaminophen $10 \mathrm{mg}$ & Single dose & $\mathrm{PO}$ & $1 / 7$ & 5.3 \\
\hline 1992 & America & Ibuprofen 7.5/10 mg & Single dose & PO & $6 / 14$ & 6.08 \\
\hline Kelley et al. & North & Acetaminophen $11.6 \mathrm{mg}$ & Single dose & PO & $6 / 10$ & 5.9 \\
\hline 1992 & America & Ibuprofen 6 mg & Single dose & PO & $9 / 8$ & 5.8 \\
\hline Khalil et al. & North & Acetaminophen $10 \mathrm{mg}$ & $\mathrm{Q} 4 \mathrm{H}$ & PO/Rectal & $26 / 27$ & 6 \\
\hline 2017 & America & Ibuprofen 10 mg & $\mathrm{Q} 4 \mathrm{H}$ & IV & $27 / 20$ & 7 \\
\hline Luo et al. & Europe & Acetaminophen $10 \mathrm{mg}$ & $\mathrm{Q} 4 \mathrm{H}$ & $\mathrm{PO}$ & $93 / 63$ & 2.65 \\
\hline 2017 & & Ibuprofen 10 mg & Q6H & $\mathrm{PO}$ & $91 / 66$ & 2.44 \\
\hline McIntyre et al. & Europe & Acetaminophen $12.5 \mathrm{mg}$ & $\mathrm{Q} 6 \mathrm{H}$ & $\mathrm{PO}$ & $47 / 27$ & 1.6 \\
\hline 1996 & & Ibuprofen $5 \mathrm{mg}$ & Q6H & PO & $42 / 34$ & 1.8 \\
\hline Nwanyanwu & Africa & Acetaminophen $12.5 \mathrm{mg}$ & $\mathrm{Q} 6 \mathrm{H}$ & $\mathrm{PO}$ & NR & NR \\
\hline et al. 1999 & & Ibuprofen $5 \mathrm{mg}$ & Q6H & PO & & \\
\hline Sarrell et al. & Middle & Acetaminophen $12.5 \mathrm{mg}$ & $\mathrm{Q} 6 \mathrm{H}$ & PO & $71 / 83$ & 1.55 \\
\hline 2006 & East & Ibuprofen 5 mg & $\mathrm{Q} 8 \mathrm{H}$ & $\mathrm{PO}$ & $73 / 82$ & 1.63 \\
\hline Seyfhashemi & Middle & Acetaminophen $15 \mathrm{mg}$ & $\mathrm{Q} 4 \mathrm{H}$ & PO & NR & NR \\
\hline et al. 2007 & East & Ibuprofen 10 mg & Q6H & $\mathrm{PO}$ & & \\
\hline Ulukol et al. & Middle & Acetaminophen $10 \mathrm{mg}$ & $\mathrm{Q} 8 \mathrm{H}$ & PO & $15 / 15$ & 5.6 \\
\hline 1999 & East & Ibuprofen $10 \mathrm{mg}$ & $\mathrm{Q} 8 \mathrm{H}$ & $\mathrm{PO}$ & $20 / 10$ & 4.7 \\
\hline Van Esch et al. & Europe & Acetaminophen $10 \mathrm{mg}$ & Q6H & $\mathrm{PO}$ & $19 / 17$ & 2.06 \\
\hline 1995 & & Ibuprofen $5 \mathrm{mg}$ & Q6H & PO & $24 / 10$ & 2.08 \\
\hline Vauzelle et al. & Europe & Acetaminophen $9.8 \mathrm{mg}$ & Single dose & $\mathrm{PO}$ & $29 / 27$ & 4.2 \\
\hline 1997 & & Ibuprofen 10.3 mg & Single dose & $\mathrm{PO}$ & $30 / 30$ & 4 \\
\hline Vyas et al. & Asia & Acetaminophen $15 \mathrm{mg}$ & Single dose & PO & $17 / 13$ & 5.56 \\
\hline 2014 & & Ibuprofen $10 \mathrm{mg}$ & Single dose & $\mathrm{PO}$ & $16 / 16$ & 6.23 \\
\hline Walson et al. & North & Acetaminophen $10 \mathrm{mg}$ & Single dose & $\mathrm{PO}$ & NR & Overall \\
\hline 1989 & America & Ibuprofen 5/10 mg & Single dose & PO & & 5.8 \\
\hline Walson et al. & North & Acetaminophen $15 \mathrm{mg}$ & Q6H & $\mathrm{PO}$ & $7 / 9$ & 5.2 \\
\hline 1992 & America & Ibuprofen 2.5/5/10 mg & Q6H & PO & $15 / 15$ & 5.35 \\
\hline Wilson et al. & North & Acetaminophen $12.5 \mathrm{mg}$ & Single dose & $\mathrm{PO}$ & NR & Overall \\
\hline 1991 & America & Ibuprofen 5/10 mg & Single dose & $\mathrm{PO}$ & & 3.36 \\
\hline Wong et al. & South & Acetaminophen $12 \mathrm{mg}$ & Single dose & $\mathrm{PO}$ & $110 / 100$ & 2.58 \\
\hline 2001 & America & Ibuprofen 5/10 mg & Single dose & PO & $118 / 91$ & 2.42 \\
\hline
\end{tabular}

$M / F-$ male/female, $N R$ - no report, $P O-$ per os, $Q 4 H-p e r 4 h$, Q6H-per $6 h$. 


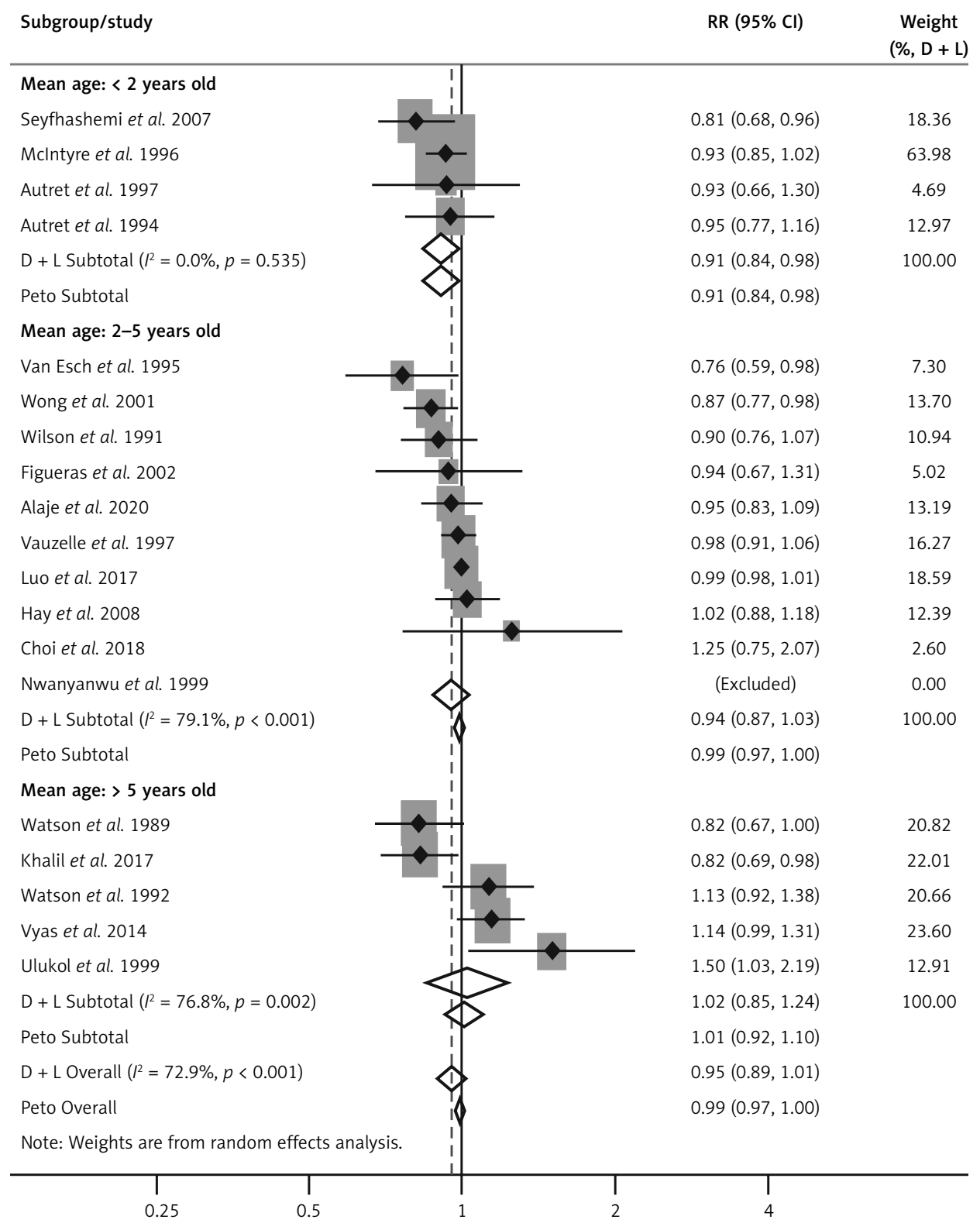

Figure 2. Forest plot for fever resolution rate between acetaminophen and ibuprofen monotherapies

\section{Discussion}

On the basis of the available evidence, the present pooled results revealed that children in the acetaminophen group displayed temperatures about $0.2^{\circ} \mathrm{C}$ higher than those in the ibuprofen group, which indicated that the efficacy of ibuprofen was slightly better than that of acetaminophen. However, this result might not be significant in clinical settings. By contrast, about 29\% lower risk was observed in the acetaminophen group than in the ibuprofen group regarding overall adverse event rates in the subgroup of mean age of $>5$ years. The safety finding may raise concerns in clinical practice.

The minimum age for using acetaminophen ranged from 0 months [46-48] to 2 months [49] and 3 months [6,50]; however, the NICE guidelines provide no suggestions for age [51]. The dosage of acetaminophen varied as follows: a single dose of $10-15$ or $>15 \mathrm{mg} / \mathrm{kg}$, intervals between doses of 4, 4-6, or $6 \mathrm{~h}$, and maximum daily dosage of $60-90 \mathrm{mg} / \mathrm{kg} / \mathrm{day}$.

Some studies have recommended 2 months [49], 3 months [50], and 6 months [6, 48] as the minimum age for ibuprofen administration, whereas no such suggestions are covered in other studies $[46,47,51]$. The dosage of ibuprofen is divergent in a single administration $(5-10$ or $10 \mathrm{mg} / \mathrm{kg} /$ dose), intervals between doses $(6,6-8 \mathrm{~h})$, and a maximum daily dosage of $40 \mathrm{mg}$ for all guidelines, except for the Italian Pediatric Society Guidelines, which allow the dose of up to 

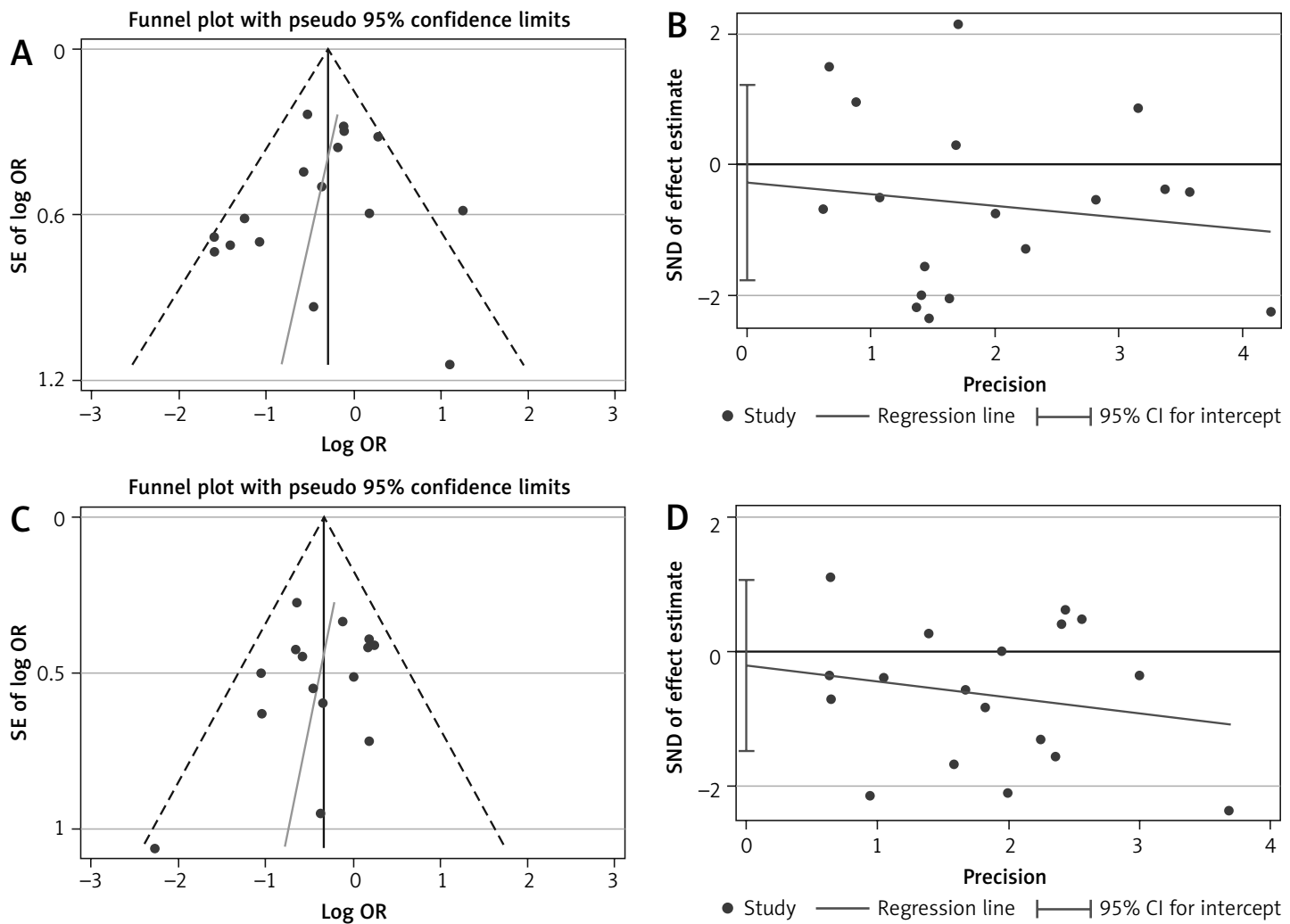

Figure 3. Small study tests using funnel plot for fever resolution rate (A), Egger's test for fever resolution rate (B), funnel plot for overall adverse event rate (C), and Egger's test for overall adverse event rate (D)

$30 \mathrm{mg}$ [47]. In the guidelines we discussed, all used either acetaminophen or ibuprofen in children with fever who appeared distressed. The choice of these two recommended antipyretics is made according to the child's age, weight, and other characteristics. In some situations, ibuprofen administration should be cautious. Ibuprofen may worsen asthma symptoms and should be prescribed cautiously [50]. In children with dehydration, ibuprofen use is contraindicated by the Italian Pediatric Society Guidelines but recommended with caution by the American Academy of Pediatrics [6] and guidelines in South Africa and South Australia [46, 50]. In the case of varicella, using ibuprofen is contraindicated by the Italian Pediatric Society Guidelines but recommended with caution by the American Academy of Pediatrics and guidelines in South Africa $[6,47,50]$. Although part of our analysis supports these guidelines, some differences were noted.

According to our analysis, in children with a mean age $<2$ years, ibuprofen was more effective than acetaminophen. The same result was observed in children with a mean age between 2 and 5 years. Moreover, the side effects compared between ibuprofen and acetaminophen demonstrated no obvious difference in groups with mean ages of under 2 years. Although ibuprofen may be preferred for a rapid antipyretic effect, more studies are required to establish its safety. In studies with a mean age of $>5$ years, no obvious difference in effectiveness was observed between acetaminophen and ibuprofen. Furthermore, acetaminophen monotherapy demonstrated fewer side effects than did ibuprofen monotherapy. As per our observations, no differences were observed in the antipyretic effects between ibuprofen monotherapy and acetaminophen monotherapy with older age.

In total, 1,329 people comprised the acetaminophen group with available fever resolution data, and the acetaminophen group was administered dosages of $9.8,10,12.5$, and $\geq 15 \mathrm{mg} / \mathrm{kg}$ (up to $30 \mathrm{mg} / \mathrm{kg}$ ). We did not observe a notable increment in antipyretic effects with increasing dosage. Out of twenty-four included studies with the oral route of medication, there was only one study with the intravenous route of acetaminophen and one study with the rectal or oral route of acetaminophen and intravenous route of ibuprofen. There was a difference in pharmacokinetics when the administration route was different, which might have led to the variation of time-related antipyretic efficacy $[52,53]$. Nevertheless, there was no outcome difference when these two studies with different routes of medication were weeded out from the analysis. Regarding the adverse effects of acetaminophen, our analysis demonstrated a trend wherein the risk of an adverse event increased, similar to that of the ibuprofen group, with an in- 


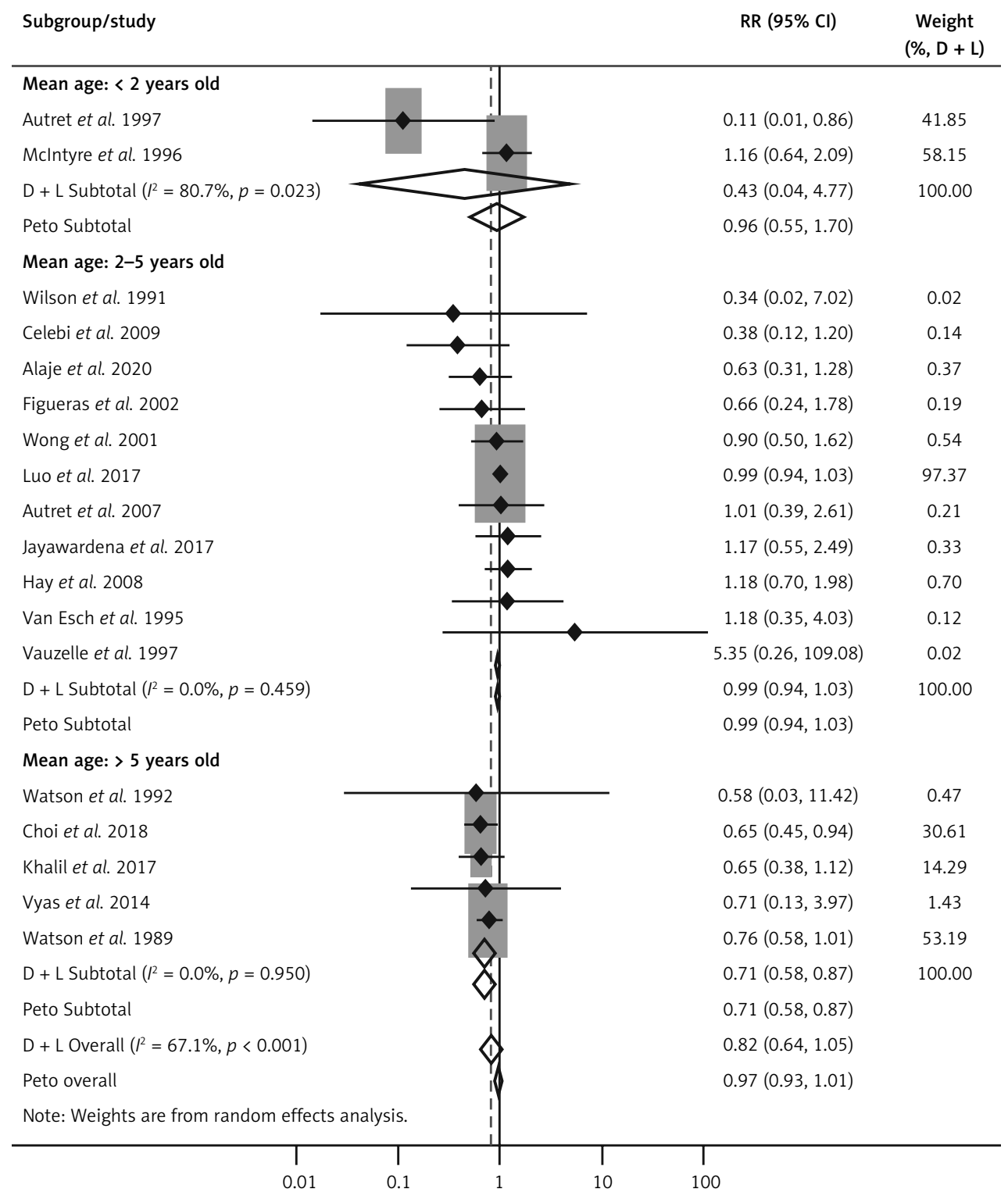

Figure 4. Forest plot for overall adverse event rate between acetaminophen and ibuprofen monotherapies

creasing acetaminophen dose. Multisystemic adverse effects caused by acetaminophen use have been mentioned in other studies including gastrointestinal (vomiting), dermatologic (skin rash), metabolic (hyponatremia), hematologic (pancytopenia), and hepatic (elevation of serum alkaline phosphatase and bilirubin). The incidence of adverse events mentioned earlier was still low, and few cases of catastrophic clinical outcomes caused by these adverse effects were reported [54, 55]. Therefore, we recommend a dosage of $10 \mathrm{mg} / \mathrm{kg}$ acetaminophen that exerts the maximum antipyretic effects with a relatively low adverse event risk. Compared with the acetaminophen group, a higher proportion of patients in the ibuprofen group developed adverse effects, especially symptoms of the gastrointestinal system. In the included studies, the gastrointestinal symptoms most documented were nausea, vomiting, abdominal pain, and diarrhea. By contrast, few studies have reported overt gastrointestinal bleeding symptoms, such as melena, hematemesis, and hematochezia, which indicated that there were not more significant events of gastrointestinal bleeding or mortality despite the higher risk of adverse effects in the ibuprofen group than in the acetaminophen group. Although the safety of ibuprofen raised little concern, subtle adverse effects attributed to medications still bother and affect the quality of life of the caregivers. Parents, who are not professionals of medicine or related fields, are extremely anxious about disease progression and adverse events caused by diseases in their children, even incurable illnesses such as the common cold [56]. Subtle adverse effects could conceivably worsen the parents' quality of life. 
Table II. Summary of findings

\begin{tabular}{|c|c|c|c|}
\hline $\begin{array}{l}\text { No. of participants } \\
\text { (studies) }\end{array}$ & $\begin{array}{l}\text { Certainty of the } \\
\text { evidence (GRADE) }\end{array}$ & $\begin{array}{l}\text { Relative effects } \\
\quad(95 \% \mathrm{Cl})\end{array}$ & Comments \\
\hline \multicolumn{4}{|c|}{ Afebrile rate (mean age: < 2 years) } \\
\hline $\begin{array}{l}620 \\
(4 \text { RCTs })\end{array}$ & $\begin{array}{l}\oplus \oplus \bigcirc \bigcirc^{\mathrm{a}, \mathrm{b}} \\
\mathrm{LOW}\end{array}$ & $\begin{array}{c}\text { POR } 0.91 \\
(0.84 \text { to } 0.98)\end{array}$ & $\begin{array}{l}\text { Acetaminophen may slightly } \\
\text { decrease afebrile rate }\end{array}$ \\
\hline \multicolumn{4}{|c|}{ Afebrile rate (mean age: $2-5$ years) } \\
\hline $\begin{array}{l}1566 \\
\text { (9 RCTs) }\end{array}$ & $\begin{array}{l}\oplus \oplus \bigcirc \bigcirc^{a, c} \\
\text { LOW }\end{array}$ & $\begin{array}{c}\text { POR } 0.99 \\
\text { (0.97 to } 1.01)\end{array}$ & $\begin{array}{c}\text { Acetaminophen does not decrease } \\
\text { afebrile rate }\end{array}$ \\
\hline \multicolumn{4}{|c|}{ Afebrile rate (mean age: $>5$ years) } \\
\hline $\begin{array}{l}353 \\
(5 \mathrm{RCTs})\end{array}$ & $\begin{array}{l}\oplus O \bigcirc O^{\mathrm{a}, \mathrm{b}, \mathrm{c}} \\
\text { VERY LOW }\end{array}$ & $\begin{array}{c}\text { POR } 1.01 \\
\text { (0.92 to } 1.10)\end{array}$ & $\begin{array}{c}\text { Acetaminophen does not increase } \\
\text { afebrile rate }\end{array}$ \\
\hline \multicolumn{4}{|c|}{ Overall complication (mean age: $<2$ years) } \\
\hline $\begin{array}{l}382 \\
(2 \text { RCTs })\end{array}$ & $\begin{array}{l}\oplus \oplus \bigcirc \bigcirc^{\mathrm{b}, \mathrm{c}} \\
\mathrm{LOW}\end{array}$ & $\begin{array}{c}\text { POR } 0.96 \\
(0.55 \text { to } 1.70)\end{array}$ & $\begin{array}{l}\text { Acetaminophen does not reduce } \\
\text { overall complication rate }\end{array}$ \\
\hline \multicolumn{4}{|c|}{ Overall complication (mean age: $2-5$ years) } \\
\hline $\begin{array}{l}2323 \\
(11 \text { RCTs })\end{array}$ & $\begin{array}{l}\oplus \oplus \oplus \mathrm{O}^{\mathrm{a}} \\
\text { MODERATE }\end{array}$ & $\begin{array}{c}\text { POR } 0.99 \\
\text { (0.94 to } 1.03)\end{array}$ & $\begin{array}{l}\text { Acetaminophen does not reduce } \\
\text { overall complication rate }\end{array}$ \\
\hline \multicolumn{4}{|c|}{ Overall complication (mean age: > 5 years) } \\
\hline $\begin{array}{l}583 \\
(5 \mathrm{RCTs})\end{array}$ & $\begin{array}{l}\oplus \oplus \oplus \mathrm{O}^{\mathrm{b}} \\
\text { MODERATE }\end{array}$ & $\begin{array}{c}\text { POR } 0.71 \\
(0.58 \text { to } 0.87)\end{array}$ & $\begin{array}{l}\text { Acetaminophen reduces overall } \\
\text { complication rate }\end{array}$ \\
\hline
\end{tabular}

$R C T$ - randomized controlled trial, POR - Peto odds ratio. ${ }^{a}$ Downgrade a level due to some concerns or high risk of bias in trials. ${ }^{b}$ Downgrade a level due to wide range of confidence interval or relatively small sample size. ${ }^{c}$ Downgrade a level due to some concerns about heterogeneity $\left(I^{2}>50 \%\right)$.

Although the present study gathered evidence more comprehensively than did the previous systematic reviews, some methodological limitations existed. First, we could not stratify the diseases underlying the pyrexia, mainly because no data that could aid in distinguishing the underlying diseases were available. Interpreting the present pooled results cautiously and considering the underlying diseases before application in clinical practice is recommended. Second, acetaminophen and ibuprofen can be administered through various strategies. However, we could not draw conclusions on the optimal medication strategy because of insufficient evidence. Future studies should discuss this further to ensure optimal treatment outcomes.

In conclusion, the present evidence provides additional information on the effects of acetaminophen and ibuprofen monotherapies in febrile children, indicating that ibuprofen might be not superior to acetaminophen even in children with mean age of approximately 5 years. Moreover, acetaminophen monotherapy may be safer than ibuprofen monotherapy, particularly in children about 5 years old. In conclusion, as the efficacy and risk of adverse events are taken into consideration comprehensively, acetaminophen monotherapy might be a better choice for antipyretic purposes in children as compared with ibuprofen monotherapy.

\section{Acknowledgments}

Ning Guo, M.D. and Nien-Yin Su, M.D. contributed equally.

\section{Conflict of interest}

The authors declare no conflict of interest.

\section{References}

1. Dixon G, Booth C, Price E, Westran R, Turner M, Klein N. Fever as nature's engine. Part of beneficial host response? BMJ 2010; 340: C450.

2. McCance KL, Huether SE. Pathophysiology: the Biologic Basis for Disease in Adults and Children. Elsevier, St. Louis, MO 2014.

3. Bilenko N, Tessler H, Okbe R, Press J, Gorodischer R. Determinants of antipyretic misuse in children up to 5 years of age: a cross-sectional study. Clin Ther 2006; 28: 783-93.

4. Barbi E, Marzuillo P, Neri E, Naviglio S, Krauss BS. Fever in children: pearls and pitfalls. Children 2017; 4: 81.

5. Kanabar DJ. A clinical and safety review of paracetamol and ibuprofen in children. Inflammopharmacology 2017; 25: 1-9.

6. Sullivan JE, Farrar HC. Fever and antipyretic use in children. Pediatrics 2011; 127: 580-7.

7. Walson PD, Galletta G, Braden NJ, et al. Ibuprofen, acetaminophen, and placebo treatment of febrile children. Clin Pharmacol Ther 1989; 46: 9-17.

8. Perrott DA, Piira T, Goodenough B, Champion GD. Efficacy and safety of acetaminophen vs ibuprofen for 
treating children's pain or fever: a meta-analysis. Arch Pediatr Adolesc Med 2004; 158: 521-6.

9. Kleijnen J. Clinical safety and tolerability of ibuprofen compared with paracetamol in pediatric pain and fever. A systematic review. Minerva Pediatr 2009; 61: 757.

10. Southey ER, Soares-Weiser K, Kleijnen J. Systematic review and meta-analysis of the clinical safety and tolerability of ibuprofen compared with paracetamol in paediatric pain and fever. Curr Med Res Opin 2009; 25 . 2207-22.

11. Tan E, Braithwaite I, McKinlay CJD, Dalziel SR. Comparison of acetaminophen (paracetamol) with ibuprofen for treatment of fever or pain in children younger than 2 years: a systematic review and meta-analysis. JAMA Netw Open 2020; 3: e2022398.

12. Autret E, Reboul-Marty J, Henry-Launois B, et al. Evaluation of ibuprofen versus aspirin and paracetamol on efficacy and comfort in children with fever. Eur J Clin Pharmacol 1997; 51: 367-71.

13. Figueras Nadal C, García de Miguel MJ, Gómez Campderá $A$, et al. Effectiveness and tolerability of ibuprofenarginine versus paracetamol in children with fever of likely infectious origin. Acta Paediatr 2002; 91: 383-90.

14. Kelley MT, Walson PD, Edge JH, Cox S, Mortensen ME. Pharmacokinetics and pharmacodynamics of ibuprofen isomers and acetaminophen in febrile children. Clin Pharmacol Ther 1992; 52: 181-9.

15. Nwanyanwu OC, Ziba C, Kazembe PN. Paracetamol and ibuprofen for treatment of fever in Malawian children aged less than five years. Trans Royal Soc Trop Med Hygiene 1999; 93: 84.

16. Ulukol B, Koksal Y, Cin S. Assessment of the efficacy and safety of paracetamol, ibuprofen and nimesulide in children with upper respiratory tract infections. Eur J Clin Pharmacol 1999; 55: 615-8.

17. Wong A, Sibbald A, Ferrero F, et al. Antipyretic effects of dipyrone versus ibuprofen versus acetaminophen in children: results of a multinational, randomized, modified double-blind study. Clin Pediatr 2001; 40: 313-24.

18. Crook J. Fever management: evaluating the use of ibuprofen and paracetamol. Nursing Children and Young People 2010; 22-6.

19. Higgins JP, Thomas J, Chandler J, et al. Cochrane Handbook for Systematic Reviews of Interventions. John Wiley \& Sons 2019.

20. Liberati A, Altman DG, Tetzlaff J, et al. The PRISMA statement for reporting systematic reviews and meta-analyses of studies that evaluate healthcare interventions: explanation and elaboration. BMJ 2009; 339: b2700.

21. Marin TM, de Carvalho Indolfo N, Rocco SA, et al. Ac etaminophen absorption and metabolism in an intestine/liver microphysiological system. Chem Biol Interact 2019; 299: 59-76.

22. Shin D, Lee SJ, Ha YM, et al. Pharmacokinetic and pharmacodynamic evaluation according to absorption differences in three formulations of ibuprofen. Drug Des Devel Ther 2017; 11: 135-41.

23. Higgins JP, Sterne JAC, Savovic J, et al. A revised tool for assessing risk of bias in randomized trials. Cochrane Database Syst Rev 2016; 10 (Suppl 1): 29-31.

24. Sterne JAC, Savovic J, Page MJ, et al. RoB 2: a revised tool for assessing risk of bias in randomised trials. BMJ 2019; 366: 14898 .

25. Ruzni N, Idris N. Modelling repeated measures data in meta analysis: an alternative approach. Sains matematik keunggulan pemikiran. 2008, Terengganu, Malaysia Universiti Malaysia Terengganu.
26. Guyatt G, Oxman AD, Akl EA, et al. GRADE guidelines: 1. Introduction - GRADE evidence profiles and summary of findings tables. J Clin Epidemiol 2011; 64: 383-94.

27. Autret E, Breart G, Jonville AP, et al. Comparative efficacy and tolerance of ibuprofen syrup and acetaminophen syrup in children with pyrexia associated with infectious diseases and treated with antibiotics. Eur J Clin Pharmacol 1994; 46: 197-201.

28. Alaje EO, Udoh EE, Akande PA, et al. Ibuprofen versus paracetamol for treating fever in preschool children in Nigeria: a randomized clinical trial of effectiveness and safety. Pan African Med J 2020; 36: 350.

29. Autret-Leca E, Gibb IA, Goulder MA. Ibuprofen versus paracetamol in pediatric fever: objective and subjective findings from a randomized, blinded study. Curr Med Res Opin 2007; 23: 2205-11.

30. Celebi S, Hacimustafaoglu M, Aygun D, et al. Antipyretic effect of ketoprofen. Indian J Pediatr 2009; 76: 287-91.

31. Choi SJ, Moon S, Choi UY, et al. The antipyretic efficacy and safety of propacetamol compared with dexibuprofen in febrile children: a multicenter, randomized, double-blind, comparative, phase 3 clinical trial. BMC Pediatr 2018; 18: 201

32. Erlewyn-Lajeunesse MD, Coppens K, Hunt LP, et al. Randomised controlled trial of combined paracetamol and ibuprofen for fever. Arch Dis Child 2006; 91: 414-6.

33. Hay AD, Costelloe C, Redmond NM, et al. Paracetamol plus ibuprofen for the treatment of fever in children (PITCH): randomised controlled trial. BMJ 2008; 337: a1302.

34. Jayawardena S, Kellstein D. Antipyretic efficacy and safety of ibuprofen versus acetaminophen suspension in febrile children: results of 2 randomized, double-blind, single-dose studies. Clin Pediatr 2017; 56: 1120-7.

35. Kauffman RE, Sawyer LA, Scheinbaum ML. Antipyretic efficacy of ibuprofen vs acetaminophen. Am J Dis Child 1992; 146: 622-5.

36. Khalil SN, Hahn BJ, Chumpitazi CE, et al. A multicenter, randomized, open-label, active-comparator trial to determine the efficacy, safety, and pharmacokinetics of intravenous ibuprofen for treatment of fever in hospitalized pediatric patients. BMC Pediatr 2017; 17: 42.

37. McIntyre J, Hull D. Comparing efficacy and tolerability of ibuprofen and paracetamol in fever. Arch Dis Child 1996; 74: 164-7.

38. Sarrell EM, Wielunsky E, Cohen HA. Antipyretic treatment in young children with fever: acetaminophen, ibuprofen, or both alternating in a randomized, doubleblind study. Arch Pediatr Adolesc Med 2006; 160: 197202.

39. Seyfhashemi M, Ghorbani R, Mehralizadeh S, Asgarzadeh S, Bahadoran P. A comparison of the antipyretic effect of acetaminophen and ibuprofen in febrile children hospitalized at Amir-Al-Momenin Hospital in Semnan, Iran. Iran J Pharmacol Ther 2007; 6: 213-0.

40. Van Esch A, Van Steensel-Moll HA, Steyerberg EW, et al. Antipyretic efficacy of ibuprofen and acetaminophen in children with febrile seizures. Arch Pediatr Adolesc Med 1995; 149: 632-7.

41. Vauzelle-Kervroedan F, d'Athis P, Pariente-Khayat A, Debregeas S, Olive G, Pons G. Equivalent antipyretic activity of ibuprofen and paracetamol in febrile children. J Pediatr 1997; 131: 683-7.

42. Vyas FI, Rana DA, Patel PM, Patel VJ, Bhavsar RH. Randomized comparative trial of efficacy of paracetamol, ibuprofen and paracetamol-ibuprofen combination for treatment of febrile children. Perspect Clin Res 2014; 5 : 25-31. 
43. Walson PD, Galletta G, Chomilo F, et al. Comparison of multidose ibuprofen and acetaminophen therapy in febrile children. Am J Dis Child 1992; 146: 626-32.

44. Wilson JT, Brown RD, Kearns GL, et al. Single-dose, placebo-controlled comparative study of ibuprofen and acetaminophen antipyresis in children. J Pediatr 1991; 119: 803-11.

45. Luo S, Ran M, Luo Q, et al. Alternating acetaminophen and ibuprofen versus monotherapies in improvements of distress and reducing refractory fever in febrile children: a randomized controlled trial. Paediatr Drugs 2017; 19: 479-86.

46. Government of South Australia. Children with Fever Aged 1-2 Months. South Australian Paediatric Clinical Practice Guideline. 2013: South Australia. Retrieved from https://www.sahealth.sa.gov.au/wps/wcm/connect/ 812 ad70040d041b4972cbf40b897efc8/Fever+ in+Children+aged+1-2+months_Paed_v3_1.pdf?MOD= AJPERES\& $a m p ; C A C H E I D=R O O T W O R K S P A C E-$ 812ad70040d041b4972cbf40b897efc8-nGoJGaw.

47. Chiappini E, Venturini E, Remaschi G, et al. 2016 Update of the Italian Pediatric Society Guidelines for management of fever in children. J Pediatr 2017; 180: 177-83.e1.

48. NSW Kids and Families. Children and Infants with Fever - Acute Management. NSW Department of Health. 2010: North Sydney NS. Retrieved from https://silo.tips/ download/children-and-infants-with-fever-acute-management.

49. WHO-GRC, WHO Guidelines Approved by the Guidelines Review Committee, in Pocket Book of Hospital Care for Children: Guidelines for the Management of Common Childhood Illnesses. World Health Organization, Geneva 2013,

50. Green R, Jeena P, Kotze $S$, et al. Management of acute fever in children: guideline for community healthcare providers and pharmacists. South African Med J 2013; 103: 948-54.

51. Team, N.G.U., National Institute for Health and Care Excellence: Clinical Guidelines, in Fever in under $5 \mathrm{~s}$ : assessment and initial management. 2019. National Institute for Health and Care Excellence (UK). NICE London 2019.

52. Khalil SN, Hahn BJ, Chumpitazi CE, et al. A multicenter, randomized, open-label, active-comparator trial to determine the efficacy, safety, and pharmacokinetics of intravenous ibuprofen for treatment of fever in hospitalized pediatric patients. BMC Pediatr 2017; 17: 42.

53. Sartini I, Łebkowska-Wieruszewska B, Lisowski A, Pharmacokinetics of acetaminophen after intravenous and oral administration in fasted and fed Labrador Retriever dogs. J Vet Pharmacol Ther 2020; 44: 28-35.

54. Amar PJ, Schiff ER. Acetaminophen safety and hepatotoxicity: where do we go from here? Expert Opin Drug Saf 2007; 6: 341-55.

55. Food U. and D. Administration. FDA drug safety communication: prescription acetaminophen products to be limited to $325 \mathrm{mg}$ per dosage unit; boxed warning will highlight potential for severe liver failure. Available at: https://www.fda.gov/drugs/drug-safety-and-availability/fda-drug-safety-communication-prescription-acetaminophen-products-be-limited-325-mg-dosage-unit 2011.

56. Pantell RH, Fries JF, Vickery DM. Taking Care of Your Child: a Parent's Illustrated Guide to Complete Medical Care. Da Capo Lifelong Books 2015. 
Appendix 1. Database and search strategy

\begin{tabular}{|c|c|}
\hline Database & Syntax \\
\hline \multirow[t]{5}{*}{ Cochrane } & \#1 fever OR pyrexia OR febrile in All Text \\
\hline & \#2 child OR children OR kids OR pediatric OR paediatric OR pediatrics OR paediatrics in All Text \\
\hline & \#3 ibuprofen in All Text \\
\hline & \#4 acetaminophen OR acetamol OR paracetamol in All Text \\
\hline & \#5 \#1 AND \#2 AND \#3 AND \#4 \\
\hline \multirow[t]{5}{*}{ PubMed } & \#1 fever OR pyrexia OR febrile \\
\hline & $\begin{array}{l}\text { \#2 infant OR infants OR child OR children OR kids OR pediatric OR paediatric OR pediatrics OR } \\
\text { paediatrics }\end{array}$ \\
\hline & \#3 ibuprofen \\
\hline & \#4 acetaminophen OR acetamol OR paracetamol \\
\hline & \#5 \#1 AND \#2 AND \#3 AND \#4 \\
\hline
\end{tabular}

\begin{tabular}{|ll|}
\hline Database & Syntax \\
\hline Embase $\quad \# 1$ ('fever'/exp OR fever OR 'body temperature elevation' OR 'febrile disease' OR 'febrile reaction'
\end{tabular}
OR 'febrile response' OR 'fever' OR 'pyrexia' OR 'sweating sickness' OR pyrexia OR febrile) \#2 ('child'/exp OR child OR 'child' OR 'children' OR kids OR ‘pediatric'/exp OR pediatric OR 'paediatric'/exp OR paediatric OR 'pediatrics'/exp OR pediatrics OR 'community paediatrics' OR 'community pediatrics' OR ‘paediatric aspect' OR 'paediatric care' OR 'paediatric educating' OR 'paediatric education' OR 'paediatric institute' OR 'paediatric internship' OR 'paediatric perspective' OR 'paediatric practice' OR 'paediatric research' OR 'paediatric service' OR 'paediatrics' OR 'paediatrics department' OR 'pediatric aspect' OR 'pediatric care' OR 'pediatric educating' OR ‘pediatric education' OR ‘pediatric institute' OR 'pediatric internship' OR 'pediatric practice' OR 'pediatric research' OR 'pediatric service' OR 'pediatrics' OR 'pediatrics department' OR 'pediatry' OR 'social pediatry' OR 'well baby clinic')

\#3 ('ibuprofen'/exp OR ibuprofen OR '2 (4 isobutylphenyl) propionic acid' OR '2 (para isobutylphenyl) propionic acid' OR '2 [4 (2 methylpropyl) phenyl] propionic acid' OR 'abfen' OR 'aches-n-pain' OR ‘act-3' OR ‘actiprofen' OR ‘adex 200' OR ‘adex liqui-gels' OR ‘advil' OR ‘advil infantil' OR ‘advil liqui-gels' OR ‘advil liquid caps' OR ‘advil liquifast' OR 'advil liquigel' OR ‘advil migraine liqui-gels' OR 'advil mono' OR ‘advil paediatric' OR 'advil pediatric' OR ‘advil ultra' OR 'advil ultra forte' OR 'advilcaps' OR ‘advileff' OR 'advilgel' OR 'advilmed' OR 'adviltab' OR 'afebril' OR ‘aktren' OR ‘aktren forte' OR 'aktren mobil' OR 'aktren spezial' OR ‘algiasdin' OR 'algiasdin retard' OR ‘algifor' OR ‘algofen' OR ‘algoflex' OR ‘algoflex forte' OR ‘algoflex norma' OR ‘algoflex rapid' OR ‘allipen' OR 'alpha (4 isobutylphenyl) propionic acid' OR 'alvofen express' OR ‘am-fam 400' OR ‘anadin (ibuprofen)' OR ‘anadin joint pain' OR ‘anadin liquifast' OR ‘anadin period pain' OR ‘anadin ultra' OR ‘anadvil' OR ‘analgyl' OR ‘anbifen' OR ‘anco' OR ‘andran' OR 'anflagen' OR ‘antalgil’ OR ‘antarene' OR ‘antiflam' OR ‘apo-ibuprofen' OR ‘aragel' OR 'atril 300' OR ‘attritin' OR ‘balkaprofen' OR ‘berlistar' OR ‘berlistar forte' OR ‘bestafen' OR ‘betaprofen' OR 'bifen' OR ‘bluton' OR 'brufanic' OR 'brufedol' OR 'brufen' OR 'brufen 400' OR 'brufen effect' OR 'brufen forte' OR 'brufen paediatric' OR 'brufen retard' OR 'brufen sr' OR 'brufort' OR 'brugesic' OR 'brumare (ibuprofen)' OR 'brumed' OR 'brupro' OR 'brupro max' OR 'buburone' OR 'bufect' OR 'bufect forte' OR 'bufohexal' OR 'bupogesic' OR 'burana' OR ‘butacortelone' OR 'butifen' OR 'caldolor' OR 'calprofen' OR 'cap-profen' OR 'cenbufen' OR 'children`s advil' OR 'children`s advilflavored' OR ‘children `s elixsure' OR 'children`s ibuprofen' OR 'children`s motrin' OR ‘childrens motrin' OR 'codral period pain' OR 'combiflam' OR 'contraneural' OR 'cuprofen' OR 'dalsy' OR 'dalsy forte' OR 'dc 7034' OR 'dc7034' OR 'dg 7034' OR ‘dg7034' OR ‘dibufen' OR ‘diffutab sr 600' OR 'dimidon' OR 'dolan fp' OR 'dolgit' OR 'dolobene ibu' OR 'dolocyl' OR 'dolodolgit' OR 'dolofen-f' OR 'dolomax' OR 'dolormin' OR 'dolval' OR 'donjust b' OR 'dorival' OR 'druisel' OR 'easifon' OR 'ecoprofen' OR ‘emflam' OR ‘emflam-200' OR ‘epobron' OR ‘ergix douleur et fievre' OR 'eudorlin extra' OR ‘eudorlin infantil' OR 'eudorlin migrane' OR 'exidol' OR 'expanfen' OR 'febratic' OR 'febryn' OR 'femapirin' OR 'fenalgic' OR 'fenbid' OR 'flamicon' OR 'flarin' OR 'focus (drug)' OR 'froben dolore e febbre' OR 'froben dolore e infiammazione' OR 'galprofen' OR 'galprofen max' OR 'gelufene' OR 'gyno-neuralgin' OR ‘h-loniten' OR ‘halprin' OR ‘haltran' OR ‘hemagene tailleur' OR 'ib-100' OR 'ibalgin' OR 'ibalgin baby' OR 'ibalgin gel' OR 'ibalgin junior' OR 'ibalgin krem' OR 'ibalgin neo' OR 'ibalgin rapidcaps' OR 'ibofen' $O R$ 'ibosure' $O R$ 'ibu' $O R$ 'ibu slow' OR 'ibu-4' OR 'ibu-6' OR 'ibu-8' OR 'ibu-slow' OR 'ibu-tab' OR 'ibu-tab 200' OR 'ibuberl' OR 'ibucalm' OR 'ibudak' OR 'ibudol' OR 'ibudolor' OR 'ibufarmalid' OR 'ibufen' OR 'ibuflam' $O R$ 'ibufug' OR 'ibugel' OR 'ibugel forte' OR 'ibugesic' $O R$ 'ibukern' $O R$ 'ibuleve' OR 'ibulgan' $O R$ 'ibuloid' OR ‘ibumetin' OR ‘ibumousse' OR ‘ibunin' OR ‘ibupen' OR ‘ibupirac' OR ‘ibuprin' OR 'ibuprocin' OR ‘ibuprofen' OR ‘ibuprofen klinge 600' OR ‘ibuprofen potassium' OR ‘ibuprofen sodium' OR 'ibuprofene' OR 'ibuprohm' OR 'ibuprom' OR 'ibuprom sport' OR 'iburon' OR 'ibusal' OR 'ibuspray' OR 'ibustar' OR 'ibustar forte' OR 'ibusynth' OR 'ibutop' OR 'ibux' OR 'ibuxin' OR 


\begin{tabular}{|c|c|}
\hline Database & Syntax \\
\hline Embase & 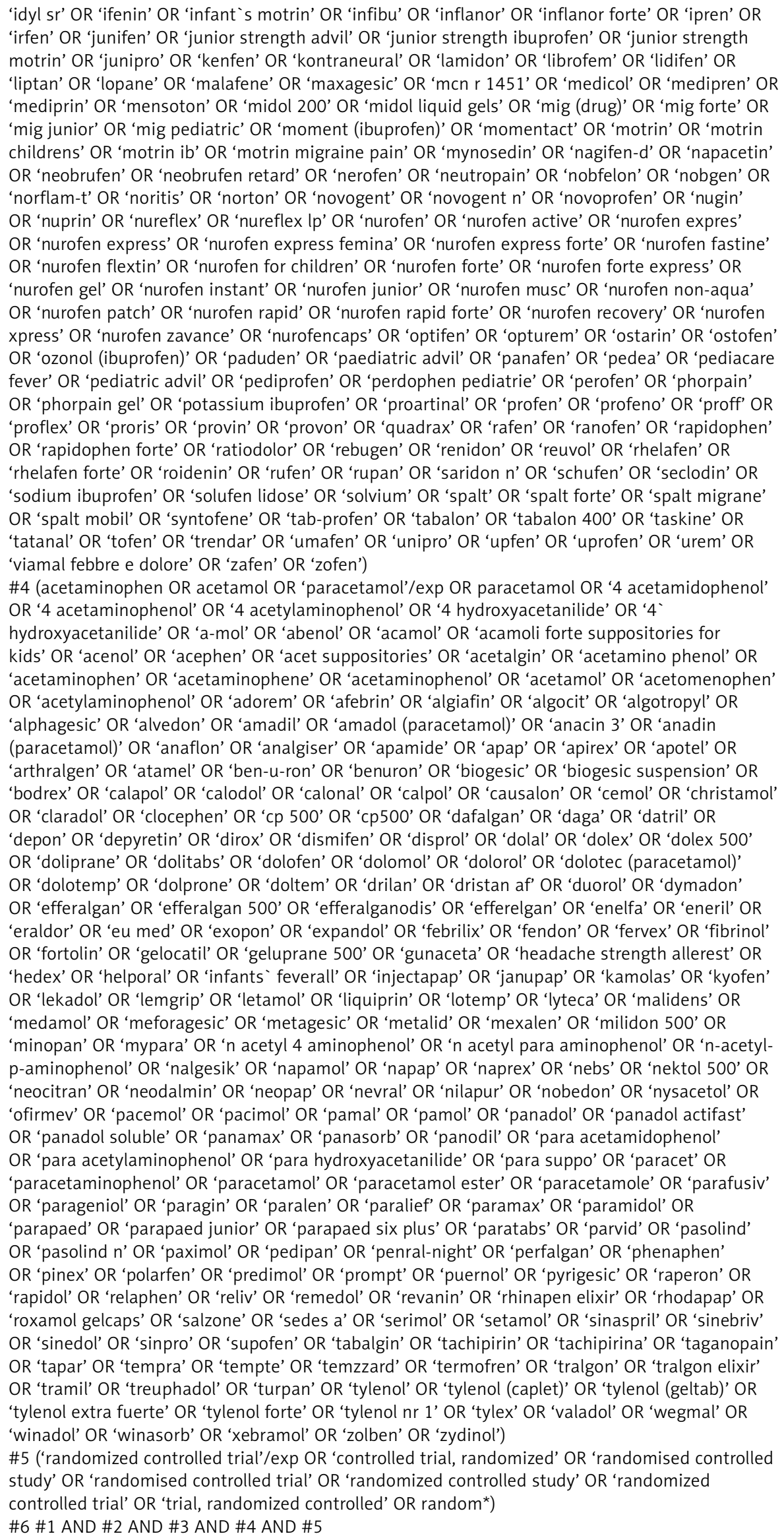 \\
\hline
\end{tabular}




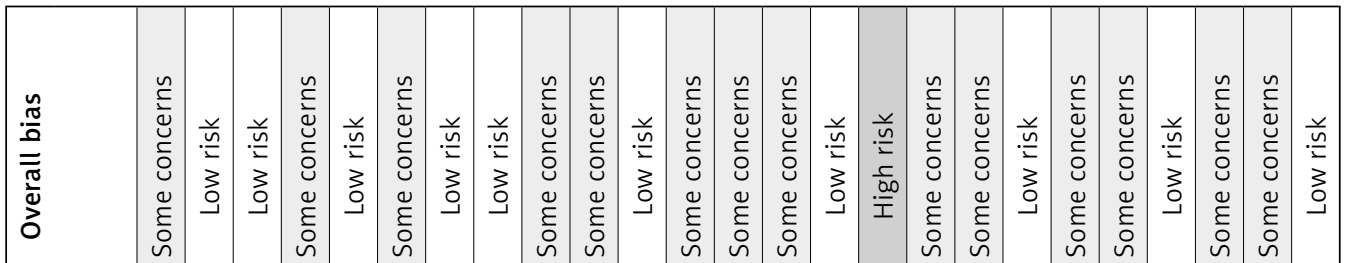

高

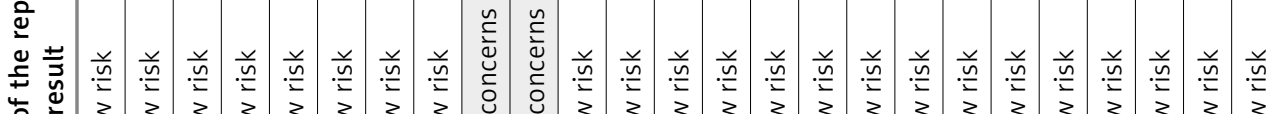

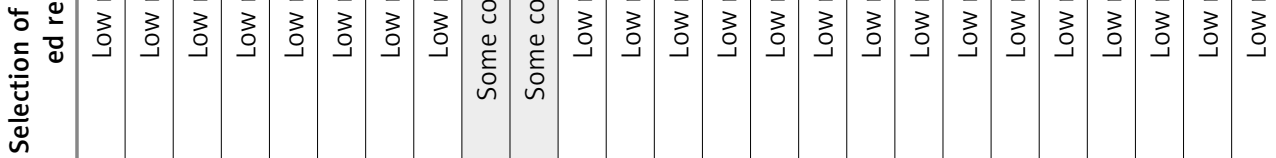

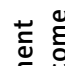

E्ष

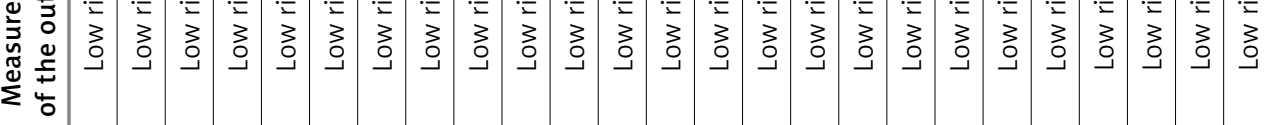

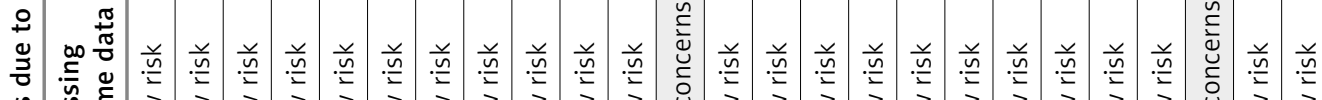

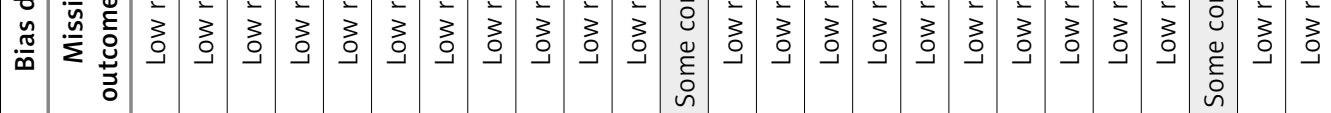

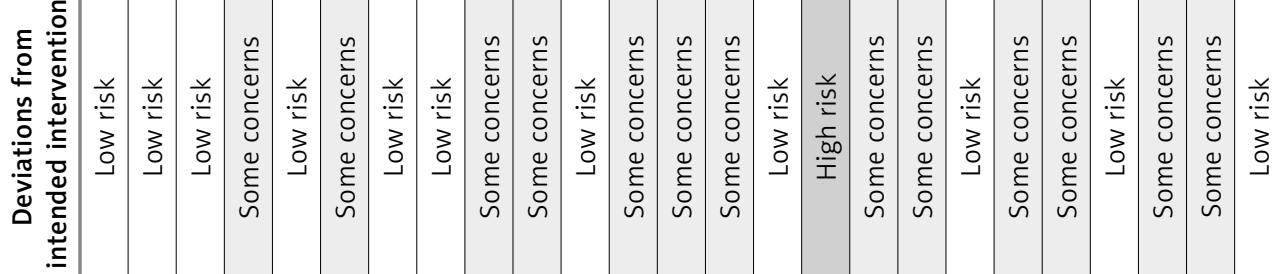

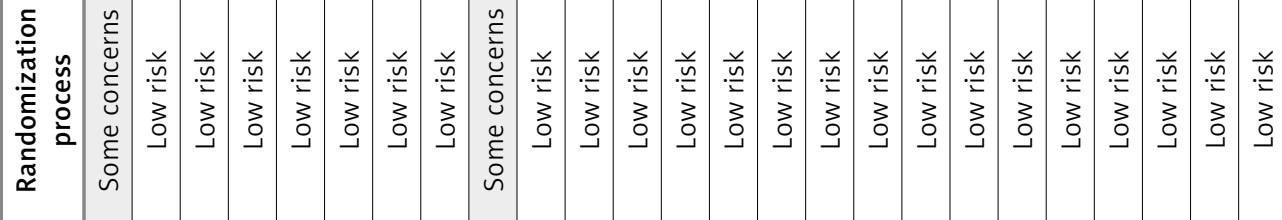

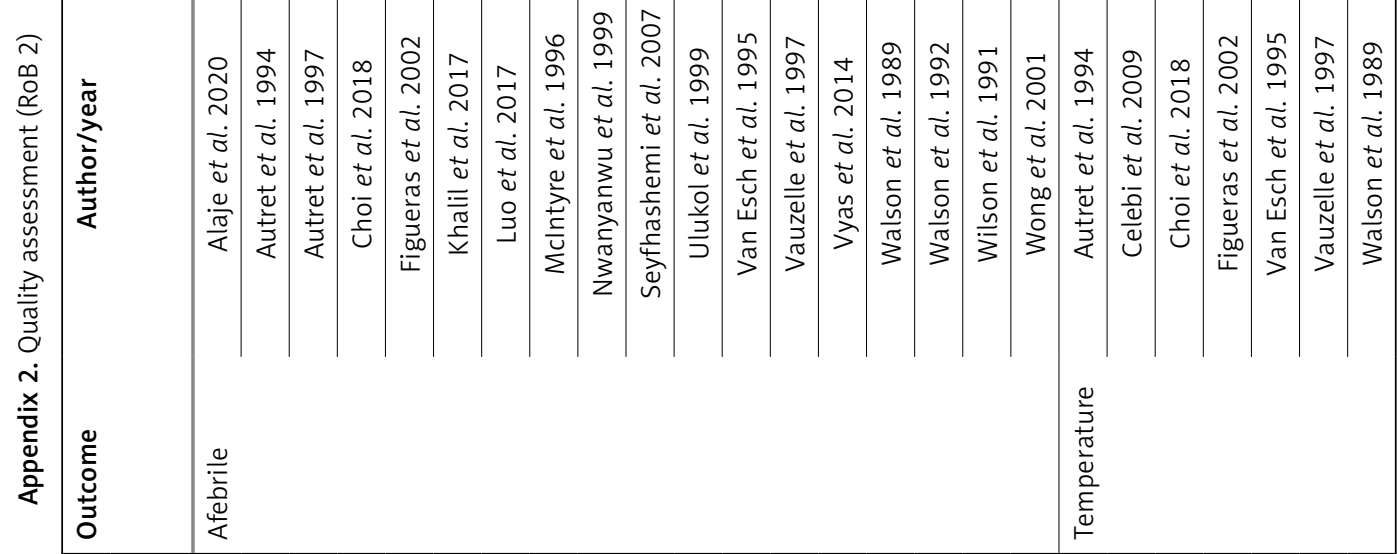




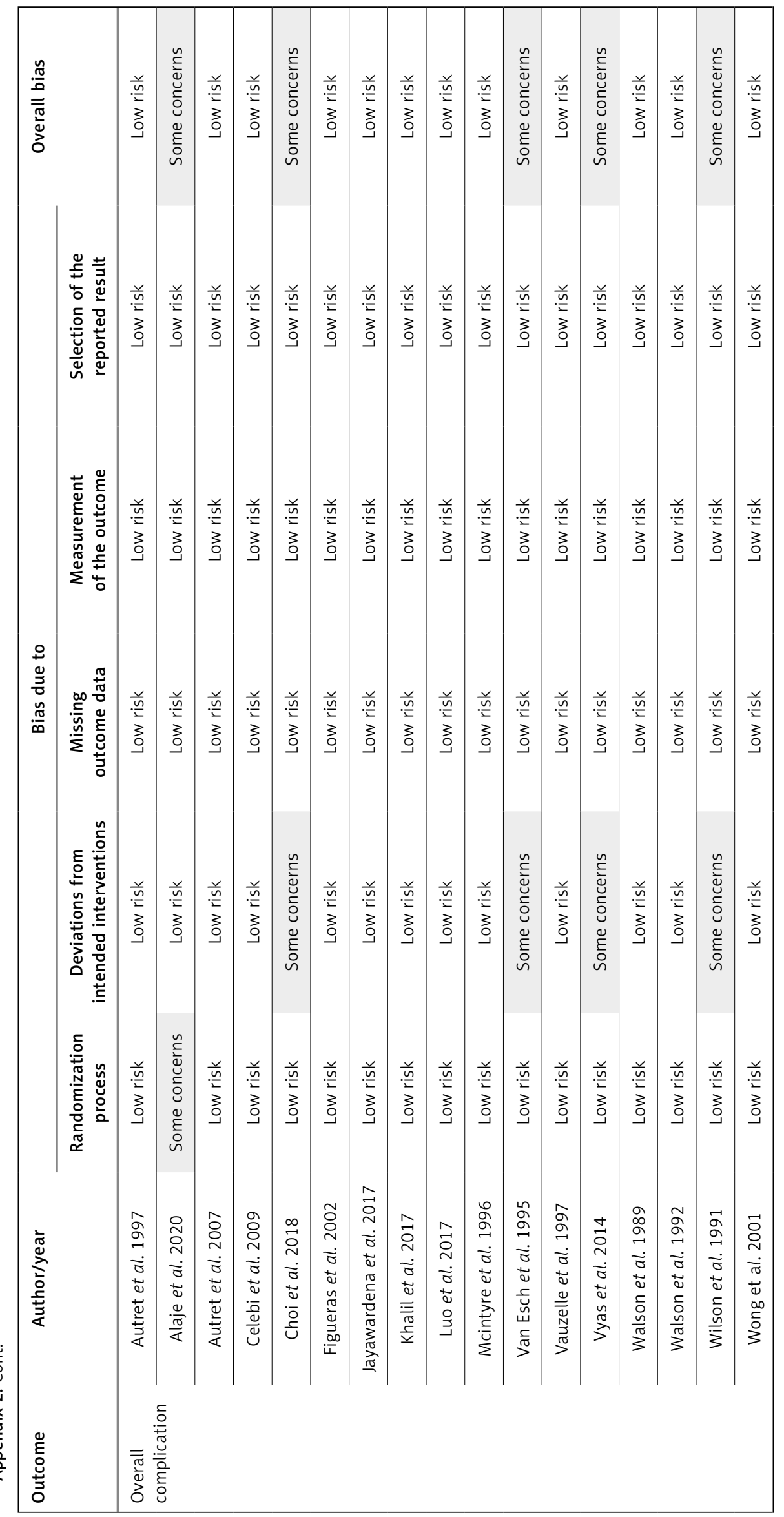


Appendix 3. Forest plot for body temperature between acetaminophen and ibuprofen monotherapies

\begin{tabular}{|c|c|c|c|c|}
\hline \multirow{2}{*}{$\begin{array}{l}\text { Time point } \\
\text { Study }\end{array}$} & \multirow[t]{2}{*}{ WMD $(95 \% \mathrm{Cl})$} & \multicolumn{2}{|c|}{$N$, mean (SD) } & \multirow{2}{*}{$\begin{array}{l}\text { Weight } \\
(\%)\end{array}$} \\
\hline & & Acetaminophen & Ibuprofen & \\
\hline \multicolumn{5}{|l|}{ Baseline } \\
\hline Kelley et al. 1992 & $-0.17(-0.51,0.18)$ & $18,39.1(0.44)$ & $18,39.3(0.61)$ & 1.60 \\
\hline Autret et al. 1997 & $-0.10(-0.20,0.00)$ & $116,39.3(0.4)$ & $116,39.4(0.4)$ & 6.55 \\
\hline Choi et at. 2018 & $-0.10(-0.22,0.02)$ & $125,38.6(0.5)$ & $138,38.7(0.5)$ & 5.89 \\
\hline Walson et al. 1992 & $-0.10(-0.25,0.05)$ & $16,39.3(0.3)$ & $30,39.4(0.094)$ & 4.89 \\
\hline Vauzelle et al. 1997 & $-0.10(-0.21,0.01)$ & $56,38.9(0.3)$ & $60,39(0.3)$ & 6.32 \\
\hline Seyfhashemi et al. 2007 & $-0.08(-0.31,0.15)$ & $50,38.7(0.58)$ & $50,38.8(0.61)$ & 2.94 \\
\hline Ulukol et al. 1999 & $-0.08(-0.30,0.14)$ & $30,38.6(0.42)$ & $30,38.7(0.43)$ & 3.28 \\
\hline Vyas et al. 2014 & $-0.08(-0.29,0.13)$ & $30,38.7(0.48)$ & $32,38.8(0.36)$ & 3.33 \\
\hline Luo et al. 2017 & $-0.01(-0.10,0.08)$ & $158,39(0.41)$ & $157,39(0.42)$ & 6.98 \\
\hline Figueras et al. 2002 & $-0.01(-0.18,0.16)$ & $93,39.1(0.56)$ & $94,39.1(0.6)$ & 4.43 \\
\hline Hay et al. 2008 & $0.00(-0.23,0.23)$ & $52,38.6(0.6)$ & $52,38.6(0.6)$ & 2.99 \\
\hline Wong et al. 2001 & $0.00(-0.12,0.12)$ & $191,39.2(0.6)$ & $185,39.2(0.6)$ & 5.87 \\
\hline Autret et al. 2007 & $0.00(-0.08,0.08)$ & $150,38.9(0.37)$ & $151,38.9(0.36)$ & 7.33 \\
\hline Celebi et al. 2009 & $0.00(-0.17,0.17)$ & $106,38.8(0.6)$ & $86,38.8(0.6)$ & 4.31 \\
\hline Jayawardena et al. 2017 & $0.00(-0.01,0.01)$ & $156,39.1(0.043)$ & $163,39.1(0.056)$ & 9.27 \\
\hline Autret et al. 1994 & $0.02(-0.21,0.25)$ & $77,39(0.76)$ & $77,39(0.72)$ & 2.93 \\
\hline Kauffman et al. 1992 & $0.10(-0.32,0.52)$ & $8,39(0.6)$ & $20,38.9(0.1)$ & 1.17 \\
\hline Van Esch et al. 1995 & $0.11(-0.27,0.49)$ & $36,39.2(0.79)$ & 34, $39.1(0.83)$ & 1.38 \\
\hline Walson et al. 1989 & $0.11(-0.05,0.27)$ & $31,39.2(0.44)$ & $54,39.1(0.081)$ & 4.72 \\
\hline Sarrell et al. 2006 & $0.16(-0.07,0.39)$ & $154,40.7(1.01)$ & $155,40.6(1.02)$ & 3.06 \\
\hline Wilson et al. 1991 & $0.18(0.14,0.22)$ & $52,37.5(0.12)$ & $90,37.4(0.121)$ & 8.73 \\
\hline Erlewyn et al. 2006 & $0.20(-0.10,0.50)$ & $37,38.9(0.68)$ & $35,38.7(0.63)$ & 2.01 \\
\hline Subtotal $\left(P^{2}=76.3 \%, p<0.001\right)$ & $-0.00(-0.05,0.05)$ & 1742 & 1827 & 100.00 \\
\hline \multicolumn{5}{|l|}{1 hour } \\
\hline Choi et at. 2018 & $-0.51(-0.66$ & $125,37.4(0.53)$ & 138, $37.9(0.69)$ & 17.61 \\
\hline Vauzelle et al. 1997 & $-0.36)$ & $56,38.3(0.6)$ & $60,38.4(0.6)$ & 16.38 \\
\hline Celebi et al. 2009 & $-0.10(-0.32,0.12)$ & $106,38(0.7)$ & $86,38.1(0.6)$ & 17.02 \\
\hline Figueras et al. 2002 & $-0.10(-0.28,0.08)$ & $93,38.1(0.72)$ & $94,37.9(0.72)$ & 16.61 \\
\hline Erlewyn et al. 2006 & $0.13(-0.08,0.34)$ & $37,38(0.47)$ & $35,37.8(0.69)$ & 15.25 \\
\hline Walson et al. 1989 & $0.17(-0.10,0.44)$ & $31,38.4(0.5)$ & $54,38.3(0.104)$ & 17.12 \\
\hline Subtotal $\left(I^{2}=89.6 \%, p<0.001\right)$ & $0.19(0.01,0.37)$ & 448 & 467 & 100.00 \\
\hline 2 hours & $-0.04(-0.29,0.20)$ & & & \\
\hline Choi et at. 2018 & & $125,37.3(0.62)$ & $138,37.4(0.6)$ & 19.67 \\
\hline Vauzelle et al. 1997 & $-0.15(-0.30$ & $55,37.9(0.7)$ & $58,37.9(0.7)$ & 15.36 \\
\hline Celebi et al. 2009 & $-0.00)$ & $106,37.7(0.7)$ & $86,37.7(0.5)$ & 18.83 \\
\hline Figueras et al. 2002 & $0.00(-0.26,0.26)$ & $93,37.7(0.78)$ & $94,37.5(0.74)$ & 16.95 \\
\hline Walson et al. 1989 & $0.00(-0.17,0.17)$ & $31,37.9(0.5)$ & $54,37.6(0.1)$ & 18.53 \\
\hline Van Esch et al. 1995 & $0.17(-0.05,0.39)$ & $29,38(0.915)$ & $30,37.6(0.602)$ & 10.65 \\
\hline Autret et al. 1994 & $0.35(0.17,0.53)$ & $77,38.1(0)$ & $77,38(0)$ & 0.00 \\
\hline Subtotal $\left(I^{2}=77.1 \%, p=0.001\right)$ & $0.36(-0.04,0.76)$ & 516 & 537 & 100.00 \\
\hline 4 hours & (Excluded) & & & \\
\hline Celebi et al. 2009 & $0.10(-0.07,0.28)$ & $106,37.5(0.7)$ & $86,37.4(0.6)$ & 28.98 \\
\hline Figueras et al. 2002 & & $93,38(1.02)$ & $84,37.8(1.05)$ & 19.45 \\
\hline Vauzelle et al. 1997 & $0.10(-0.08,0.28)$ & $55,37.8(0.8)$ & $58,37.6(0.8)$ & 20.15 \\
\hline Walson et al. 1989 & $0.15(-0.16,0.46)$ & $31,37.9(0.72)$ & $54,37.4(0.154)$ & 22.93 \\
\hline Van Esch et al. 1995 & $0.20(-0.10,0.50)$ & $31,38(1.28)$ & $31,37.4(1)$ & 8.49 \\
\hline \multirow{2}{*}{$\begin{array}{l}\text { Van Esch et al. } 1995 \\
\text { Subtotal }\left(l^{2}=52.5 \%, p=0.077\right)\end{array}$} & $0.52(0.26,0.78)$ & 316 & 313 & 100.00 \\
\hline & $0.57(-0.00,1.14)$ & & & \\
\hline 6 hours & $0.27(0.08,0.45)$ & $55,38(0.8)$ & $56,38(0.8)$ & 31.90 \\
\hline Vauzelle et al. 1997 & & $93,38.1(0.97)$ & $94,37.9(0.96)$ & 35.09 \\
\hline Figueras et al. 2002 & $0.00(-0.30,0.30)$ & $35,38.2(1.3)$ & $34,37.8(1.28)$ & 10.20 \\
\hline Van Esch et al. 1995 & $0.23(-0.05,0.51)$ & $31,38.2(1.05)$ & $54,37.8(0.224)$ & 22.81 \\
\hline Walson et al. 1989 & $0.41(-0.20,1.02)$ & 214 & 238 & 100.00 \\
\hline Subtotal $\left(R^{2}=25.9 \%, p=0.256\right)$ & $0.46(0.08,0.84)$ & & & \\
\hline Note: Weights are from random effects analysis. & $0.23(0.02,0.43)$ & & & \\
\hline
\end{tabular}


Appendix 4. Forest plot for body temperature in treatment-time interaction

Effect source

Study

Treatment effects

Van Esch et al. 1995

Walson et al. 1989

Autret et al. 1994

Figueras et al. 2002

Celebi et al. 2009

Vauzelle et al. 1997

Choi et at. 2018

Subtotal $\left(I^{2}=0.0 \%, p=0.994\right)$

\section{Time effects}

Choi et al. 2018

Celebi et al. 2009

Van Esch et al. 1995

Walson et al. 1989

Vauzelle et al. 1997

Figueras et al. 2002

Autret et al. 1994

Subtotal $\left(I^{2}=6.9 \%, p=0.375\right)$

\section{Treatment-time interaction}

Walson et al. 1989

Van Esch et al. 1995

Vauzelle et al. 1997

Autret et al. 1994

Celebi et al. 2009

Figueras et al. 2002

Choi et al. 2018

Subtotal $\left(R^{2}=0.0 \%, p=1.000\right)$

Note: Weights are from random effects analysis.
Study ES (95\% CI) Weight

(\%)

$-0.30(-1.71,1.10)$

$-0.12(-1.51,1.27) \quad 5.16$

$-0.12(-0.85,0.61) \quad 18.60$

$-0.08(-1.20,1.04) \quad 7.89$

$0.03(-0.61,0.66) \quad 24.91$

$0.09(-0.56,0.74) \quad 23.41$

$0.23(-0.59,1.04) \quad 15.02$

$0.01(-0.30,0.33) \quad 100.00$

$-0.70(-1.17,-0.23) \quad 3.81$

$-0.31(-0.50,-0.11) \quad 19.82$

$-0.18(-0.47,0.12) \quad 9.28$

$-0.17(-0.64,0.29) \quad 3.85$

$-0.17(-0.33,-0.00) \quad 27.59$

$-0.14(-0.40,0.12) \quad 11.88$

$-0.12(-0.30,0.05) \quad 23.77$

$-0.20(-0.30,-0.11) \quad 100.00$

$-0.08(-0.58,0.42) \quad 5.83$

$-0.05(-0.47,0.37) \quad 8.34$

$-0.03(-0.26,0.20) \quad 27.74$

$-0.03(-0.27,0.21) \quad 25.08$

$-0.03(-0.31,0.25) \quad 18.83$

$-0.03(-0.40,0.34) \quad 10.73$

$0.04(-0.61,0.69) \quad 3.44$

$-0.03(-0.15,0.09) \quad 100.00$ 